\title{
PERSEPSI WISATAWAN MANCANEGARA TERHADAP KUALITAS PELAYANAN PEMANDU WISATA DI DESA WISATA PINGE, KECAMATAN MARGA KABUPATEN TABANAN
}

\author{
I Kadek Edi Dana Arta \\ Ni Putu Eka Mahadewi \\ Luh Gede Leli Kusuma Dewi \\ Email : ikadekedidanaarta@gmail.com \\ PS. S1 Industri Perjalanan Wisata \\ Fakultas Pariwisata UNUD
}

\begin{abstract}
ABSTRAK
Kualitas pelayanan pemandu wisata di Desa Wisata Pinge akan berdampak terhadap kepuasan wisatawan yang berkunjung ke desa wisata pinge. Sehingga, kualitas pelayanan pemandu wisata menjadi tolak ukur dalam menentukan kepuasan wisatawan. Rumusan masalah yang diangkat adalah (1) bagaimana persepsi wisatawan mancanegara terhadap kualitas pelayanan pemandu wisata di Desa Wisata Pinge, Kecamatan Marga, Kabupaten Tabanan. Pengumpulan data dilakukan dengan observasi, wawancara mendalam, kuesioner dan studi kepustakaan. Berdasarkan hasil analisis data menunjukkan bahwa wisatawan merasa kurang puas terhadap kualitas pelayanan pemandu wisata di desa wisata pinge, dengan tingkat kesesuaian sebesar 97,04\%, dengan rata-rata tingkat kepentingan 4,19 yang berarti penting dan rata-rata tingkat kinerja sebesar 4,00 yang berarti penting sedangkan faktor-faktor yang dianggap penting dan perlu mendapat prioritas dengan tingkat kesesuaia yang kecil adalah Perhatian pemandu wisata terhadap keinginan dan kebutuhan wisatawan, kelengkapan perlengkapan pamandu wisata ( air dan pengeras suara), Inisiatif pemandu wisata dalam mengantisipasi masalah dan hambatan yang mungkin didapat selama dalam pemanduan, keandalan pemandu wisata dalam memberikan pelayanan sesuai dengan janji yang diberikan pada wisatawan.
\end{abstract}

Kata Kunci : Desa Wisata Pinge, Kepuasan Wisatawan, Kepuasan Wisatawan Mancanegara, Kualitas Pelayanan Pemandu Wisata.

\section{LATAR BELAKANG}

Keberadaan Provinsi Bali sebagai daerah tujuan wisata didukung oleh keunikan adat istiadat dan budaya yang ada di Pulau Bali yang bernafaskan Agama Hindu sebagai agama mayoritas yang dianut oleh masyarakat di Pulau Bali Serta alam di Pulau Bali yang masih asri dan indah turut serta menjadi modal utama di dalam pengembangan kepariwisataan di Pulau Bali hingga kini. Dari delapan kabupaten dan satu kota madya di Provinsi Bali, ada satu yang fokus mengembangkan daya tarik wisata alam yang dimiliki, yaitu Kabupaten Tabanan, Kabupaten Tabanan juga dikenal sebagai lumbung padi di Provinsi Bali, dengan luas wilayah sebesar $839,33 \mathrm{~km}^{2}$ dan dengan jumlah penduduk sebanyak 495.550 jiwa yang umumnya berprofesi sebagai petani. Kabupaten Tabanan selain fokus mengembangkan daya tarik wisata alam saat ini juga mengembangkan Desa wisata,menurut penuturan Wayan Adnyana selaku kepala Dinas Pariwisata dan Kebudayaan Kabupaten Tabanan terdapat 8 Desa Wisata yang dikembangkan oleh pemerintah Kabupaten Tabanan yaituDesa Wisata Pinge Tua, Antapan, Sudimara, Kerobokan, Mekar Sari, Jatiluwih, Tegal lingga dan Desa Wisata Belimbing, namun baru Desa Wisata Pinge yang mampu berkembang dan menarik minat wisatawan yang berkunjung, Desa Pinge yang merupakan salah satu desa yang ada di Kecamatan Marga, Kabupaten Tabanan yang cukup terkenal karena memiliki pemandangan yang indah dan terletak pada jalur wisata menuju Jatiluwih adapun Agent Perjalanan Wisata yang berkerjasama dengan Desa Wisata Pinge yaitu Azzimuth Tour and Travell, Talisman, 
Kampung Kita, dan Awiwa Experience, pemandu dari Agen Perjalanan Wisata inilah yang menangani seluruh kegiatan yang dilakukan oleh wisatawan saat berkunjung ke Desa Wisata Pinge. Untuk itu diketahui bagaimana persepsi wisatawan mancanegara terhadap kualitas pelayanan pemandu wisata di Desa Wisata Pinge, Kecamatan Marga Kabupaten Tabanan.

Konsep-konsep yang digunakan adalah konsep persepsi, Persepsi dalam bahasa inggris "Perseption" didefinisikan sebagai suatu tanggapan terhadap sesuatu dengan jalan asosiasi dengan ingatan tertentu. Echol (dalam I Gede Marheddy Eka Saputra.10: 2012). Konsep pelayanan, pelayanan merupakan aktivitas, manfaat, atau kepuasan yang ditawarkan untuk dijual. Dengan kata lain pelayanan merupakan suatu komoditas yang dapat dijual kepada orang lain Tjiptono (dalam Aditya Hermawan, 2013:11). Desa wisata adalah suatu bentuk inegrasi antara atraksi, akomodasi dan fasilitas pendukung yang disajikan dalam suatu struktur kehidupan masyarakat yang menyatu dengan tata cara dan tradisi yang berlaku Wiendu (dalam Perbawa Andika. 1993 : 28). Kualitas Pelayanan berpusat pada upaya pemenuhan kebutuhan dan keinginan pelanggan serta ketapatan penyampaian untuk mengimbangi harapan pelanggan Nasutioan (dalam Ayu Bismayani, 2006:20). Kepuasan pelanggan merupakan suatu hal yang menjadi harapan perusahaankhususnya dibidang hospitaliti. Kepuasan diperoleh apabila kebutuhan dan keinginan pelanggan terpenuhi, sedangkan keinginan dan kebutuhan manusia selalu berubah dan tidak ada batasnya Oliver (dalam suwintari eka. 2006 : 16).

\section{METODE}

Desa Wisata Pinge terletak di " Desa Baru " Kecamatan Marga Kabupaten Tabanan sekitar 40 kilometer utara Denpasar, Pinge Village merupakan bagian dari kabupaten Marga yang terletak $17 \mathrm{~km}$ di sebelah utara Kabupaten Tabanan, luas wilayah Desa Wisata Pinge Tua yaitu 240,75 Ha yang meliputi : Fasilitas umum dengan luas 5,75 Ha, sawah dengan luas $105 \mathrm{Ha}$ dan tegalan dengan luas 120 Ha dengan batas Desa pekraman yaitu : sebelah utara desa pakraman Tegeh, sebelah selatan Tegal Sepit, sebelah barat Pangkung Bangka dan sebelah Timur Tukad Yeh Kajang.

Definisi Oprasional Variabel yang digunakan adalah bukti langsung (tangible), empati (empathy), keandalan (reability), daya tangkap (responsiveness) dan jaminan (assurance).

Terdapat dua jenis data yaitu data kualitatif dan data kuantitatif, kemudian sumber data yaitu data primer dan data skunder, dan teknik pengumpulan data yaitu dengan cara observasi, wawancara mendalam, penyebaran kuesioner, studi kepustakaan dan dokumentasi.

Teknik analisis data yang digunakan yaitu teknik analisis deskriptif kuantitatif.

\section{HASIL}

Letak Indikator Kualitas pelayanan

Pemandu Wisata Dalam Diagram Kartesius

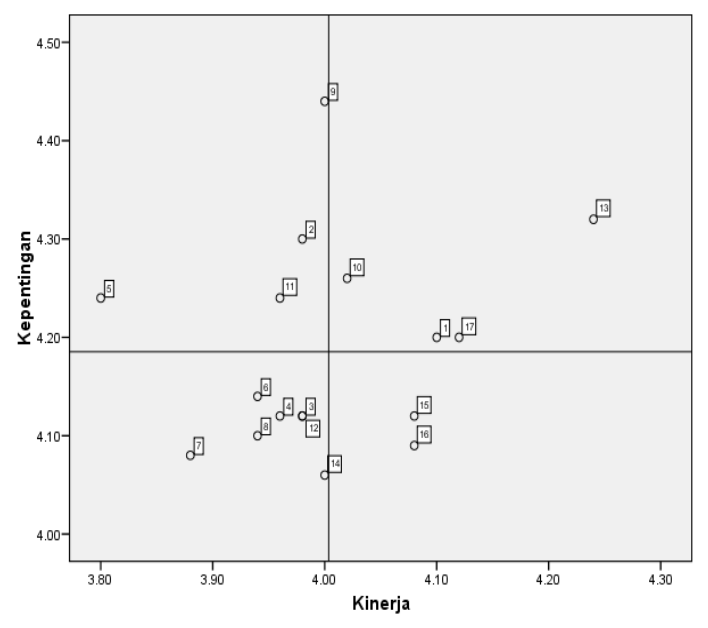

Hasil dari diagram kartesius menunjukkan indikator yang berada di Kuadran A yaitu

a. Perhatian pemandu wisata terhadap keinginan dan kebutuhan wisatawan.

b. Kelengkapan perlengkapan pamandu wisata ( air dan pengeras suara)

c. Inisiatif pemandu wisata dalam mengantisipasi masalah dan hambatan yang mungkin didapat selama dalam pemanduan.

d. Keandalan pemandu wisata dalam memberikan pelayanan sesuai dengan janji yang diberikan pada wisatawan. 
Kuadran B yaitu:
a. Inisiatif pemandu wisata dalam membantu wisatawan.
b. Kerapian penampilan pemandu wisata.
c. Kemampuan pemandu wisata dalam menjaga keamanan barang berharga wisatawan.
d. Kemampuan pemandu wisata dalam menimbulkan rasa percaya diri, aman dan nyaman pada diri wisatawan.

Kuadran C yaitu:
a. Perhatian pemandu wisata terhadap pertanyaan dari wisatawan.
b. Perhatian pemandu wisata terhadap keinginan dan kebutuhan wisatawan.
c. Keandalan pemandu wisata dalam memenuhi keinginan dan kebutuhan wisatawan.
d. Keandalan pemandu wisata dalam prosedur penarimaan wisatawan dan saat pemanduan wisatawan.

e. Ketepatan dan kesesuaian waktu pemandu wisata saat melakukan kegiatan wisata.

f. Inisiatif pemandu wisata dalam memenuhi permintaan khusus dari wisatawan.

g. Kesopanan dan keramahan pemandu wisata dalam pemanduan.

Kuadran D yaitu:

a. Kemampuan berbahasa pemandu wisata dalam berbahasa asing, khususnya dalam berbahasa inggris.

b. Pengetahuan pemandu wisata terhadap atraksi wisata meliputi sejarah, cerita unik dan larangan yang ada di Desa Wisata Pinge.

\section{PEMBAHASAN}

Sejarah Desa pinge diawali dari perjalanan Ida Dalem Jawi yang ditemani oleh I Gusti Ngurah Pacung dari munduk bias menuju Pucak Asah, setelah berjalan cukup jauh kemudian beliau beristirahat dibawah taru pinge ( Pohon pinge ), dibawah pohon pinge tersebut Ida Dalem jawi melakukan tapa yoga semadi, sedangkan pengikut beliau beliau menebang pohon yang ada disekitar pohon pinge tempat beliau melakukan tapa yoga semadi untuk membuat sebuah taman yang diberi nama taman taman bagendra. Setelah beliau melakukan tapa yoga semadi beliau beserta pengikutnya kembali melakukan perjalanan menuju Pucak Asah setelah beliau tiba di Pucak asah kemudian beliau melakukan tapa yoga semadi dan akhirnya Ida Dalem Jawi moksa sedangkan I Gusti Ngurah Pacung mendapat anugrah sebagai anglurah di perean yang bergelar I Gusti Ngurah Pacung Sakti.

Pohon pinge yang menjadi tempat Ida

Dalem Jawi melakukan tapa yoga semadi saat melakukan perjalanan menuju Pucak Asah kemudian ditempati oleh parapengembala mereka mendirikan gubuk

yang tempatnya tidak beraturan, daerah/wilayah pohon pinge tersebut dikuasai oleh Puri Marga, saat itu Ida Anak Agung Gede Pejenengan dari Puri Marga setiap hari mencium bau yang harum kemudian beliau mengutus adiknya untuk mencari sumber dari mana bau tersebut berasal akhirnya diketahuilah bau yang harum tersebut berasal dari bau bunga pohon pinge tempat Ida Dalem Jawi melakukan tapa yoga semadi saat menuju Pucak Asah, beliau memperhatikan disekitar pohon pinge tersebut terdapat terdapat rumahrumah atau pondok yang belum teratur kemudian beliau mengutus pamannya I Gusti Geluntung untuk menata rumah, penduduk dan area suci untuk melakukan persembahyangan bagi penduduk setempat yang di beri nama pura natar jemeng setelah rumah, penduduk dan area suci tertata kemudian beliau memberikan nama Desa Adat Pekraman Pinge hingga saat ini.

\section{Potensi Desa Wisata Pinge \\ Adapun potensi yang dimiliki Desa Wisata Pinge yaitu}

a). Tracking ada tiga jalur tracking yang dimili oleh Desa Wisata Pinge yaitu melewati subak pacung denga panjang jalur $8 \mathrm{~km}$ dengan waktu tempuh 2 jam, subak pinge dengan pajang jalur $12 \mathrm{~km}$ dengan waktu tempuh 3 jam dan jalur melewati Desa Pinge dengan panjang jalur $3 \mathrm{~km}$.

b). Cycling dengan start point jatiluwih menuju angsri dan berakhir di Desa Pinge.

3. Tarian Leko merupakan asal mula tarian legong keraton namun perbedaannya terletak pada instrumen yang mengiringi tarian leko yaitu rindik. 
c). Kesenian Bumbung Gebyog yaitu alat musik yang terbuat dari babu dan dipotong dengan ukuran yang berbeda kemudian dimainkan dengan cara dipukul atau dihentakkan ke tanah sehingga menghasilkan suara yang khas dan berirama.

\section{Karakteristik Responden.}

Adapun karakteristik dari 100 responden sebagai berikut.

a). Karakteristik responden berdasarkan jenis kelamin, dari 100 responden diperoleh hasil bahwa responden laki-laki sebesar 55\% dengan jumlah sebanyak 55 responden, sedangkan perempuan sebesar $45 \%$ dengan jumlah responden 45 responden. Jadi, dalam penelitian ini responden yang terbanyak adalah responden berjenis kelamin laki-laki.

b). Karakteristik wisatawan berdasarkan umur, dari 100 responden diperoleh hasil responden dengan kelompok usia 17-21 tahun yaitu sebesar $20 \%$ sebanyak 20 responden, usia $22-$ 26 tahun yaitu sebesar $40 \%$ sebanyak 40 orang dan pada usia 27 tahun keatas sebesar $40 \%$ sebanyak 40 respoden jadi dalam penelitian ini responden terbanyak yaitu responden dengan usia 22-26 tahun dan 27 tahun keatas.

c). Karakteristik responden berasarkan status, dari 100 responden diperoleh hasil responden bahwa status pernikahan responden dengan status single yaitu sebesar $22 \%$ sebanyak 22 responden, kemudian responden dengan status menikah $70 \%$ sebanyak 70 responden dan bercerai sebanyak $8 \%$ dengan jumlah 8 responden. Jadi status responden didominasi oleh responden dengan status menikah.

Berdasarkan 100 responden wisatawan mancanegara di peroleh hasil bahwa persepsi wisatawan mancanegara terhadap kualitas pelayanan pemandu wisata di Desa Wisata Pinge, Kecamatan Marga, Kabupaten Tabanan, wisatawan merasa kurang puas terhadap kualitas pelayanan pemandu wisata di Desa Wisata Pinge hal tersebut dapat dilihat dari rata-rata tingkat keesuaian sebesar $97,04 \%$. Indikator-indikator yang dianggap sangat penting oleh wisatawan namun pelaksanaanya masih perlu ditingkatkan yaitu perhatian pemandu wisata terhadap keinginan dan kebutuhan wisatawan, kelengkapan perlengkapan pamandu wisata ( air dan pengeras suara), inisiatif pemandu wisata dalam mengantisipasi masalah dan hambatan yang mungkin didapat selama dalam pemanduan, keandalan pemandu wisata dalam memberikan pelayanan sesuai dengan janji yang diberikan pada wisatawan.

\section{SIMPULAN}

Berdasarkan dari 100 responden wisatawan mancanegara diperoleh hasil bahwa persepsi wisatawan mancanegara terhadap kualitas pemandu wisata di Desa Wisata Pinge, Kecamatan Marga, Kabupaten Tabanan, wisatawan merasa kurang puas terhadap kualitas pelayanan pemandu wisata hal tersebut dapat dilhat dari rata-rata tingkat kesesuaian yang diperoleh sebesar 97,04\%.

Untuk penilaian responden yang mengguakan jasa pemandu wisata di Desa Wisata Pinge didapat hasil penilaian responden dengan bobot tertinggi berdasarkan tingkat kepentingan yaitu sebesar 444 pada indikator keandalan pemandu wisata dalam memberikan pelayanan sesuai dengan janji yang diberikan kepada wisatawan, dan bobot terendah yaitu sebesar 408 pada indikator keandalan pemandu wisata dalam rosedur penerimaan wisatawan dan saat pemanduan wisatawan. Sedangkan dari tingkat kinerja bobot tertnggi yaitu sebesar 424 pada indikator kemampuan pemandu wisata dalam menimbulkan rasa percaya diri aman dan nyaman pada diri wisatawan, dan bobot terendah yaitu sebesar 388 yaitu pada indikator indikator keandalan pemandu wisata dalam rosedur penerimaan wisatawan dan saat pemanduan wisatawan.

\section{SARAN}

Dari hasil yang telah dipaparkan diatas maka terdapat beberapa saran yang dapat diberikan yang sekiranya dapat membantu serta bermamfaat bagi pihak-pihak yang berkepentingan yaitu:

1. Diharapkan agar pemerintah Kabupaten Tabanan khususnya kepada Dinas Pariwisata Kabupaten Tabanan untuk memberikan penyuluhan dan pelatihan yang lebih banyak kepada pengelola maupun masyarakat desa wisata pinge agar dapat meningkatkan kualitas pelayanan sehingga wisatawan merasa puas berkunjung ke desa wisata pinge. 
2. Diharapkan agar badan pengelola desa wisata pinge membentuk atau merekrut generasi muda sebagai pemandu wisata lokal sehingga seluruh kegiatan wisata di desa wisata pinge ditangani oleh masyarakat lokal dan informasi yang diberikan kepada wisatawan lebih relepan.

3. Diharapkan agar badan pengelola desa wisata pinge membuat buku pedoman tentang atraksi yang dimiliki oleh desa wisata pinge sehingga informasi yang diberikan oleh pemandu wisata kepada wisatawan dapat dipertanggung jawabkan.

4. Diharapkan pemandu wisata lebih meningkatkan kualitas pelayanan yang diberikan kepada wisatawan, khususnya pada perhatian pemandu wisata terhadap keluhan dan masalah wisatawan, Keandalan pemandu wisata dalam memberikan pelayanan sesuai dengan janji yang diberikan pada wisatawan, kelengkapan perlengkapan pemandu wisata (air dan pengeras suara) dan inisiatif pemandu wisata dalam mengantisipasi masalah dan hambatan yang mungkin didapat selama dalam pemanduan, karena keempat atribut tersebut dirasa sangat penting bagi wisatawan.

\section{Daftar Pustaka}

Anindikha Vicensia Dewata. 2014. Analisis Kualitas Villa Wayang di Kuta UtaraBali Terhadap Tingkat Kepuasan Wisatawan yang Menginap. Skripsi. Unud

Bismayani, Ayu. 2007. Analisis Kualitas Jasa Pelayanan Receptionist Terhadap Tingkat Kepuasan Wisatawan Di Hotel Melia Benoa, Nusa Dua Badug. Skripsi. Unud.

Chandra Dewi Ni Kadek. 2006. Analisis Kualitas Pelayanan Pramusaji Terhadap Tingkat Kepuasan Wisatawan pada Center Stage di Hardrock Hotell Bali. Skripsi. Unud.

Debora, Vera. 2009. Pengaruh Pelayanan Pramuwisata Terhadap Kunjungan Wisatawan ke Istana Maimoon. Jurnal. Universitas Indonesia.
Dharmayanti. 2003. Analisis Tingkat Kepuasan Wisatawan Terhadap Kualitas Jasa pada Travel Nusa Dua Bali Tour di Kuta. Skripsi. Unud.

Hermawan, Aditya. 2013. Analisis Kualitas Layanan Pemandu Wisata Lokal Terhadap Tingkat Kepuasan Wisatawan Mancanegara Di Daya Tarik Wisata Alas Kedaton. Skripsi. Unud.

Kariyana, I Wayan. 2014. Analisis Kualitas Pelayanan Room Attendent terhadap Tingkat Kepuasan Wisatawan Di Bali Mandira Beach Resort And Spa Legian Bali. Skripsi. Unud.

Muhajir. 2005. Menjadi Pemandu Wisata Pemula. Jakarta : PT. Pustaka Utama.

Mursid, M. 2003.manajemen Pemasaran. Jakarta : PT.Pustaka Utama.

Pantiyasa I Wayan dan Ni Putu Diah Prabawati Ni Putu. 2014. Servqual Pramugraha Dalam Penyiapan Kamar Di desa Wisata. Jurnal. Politeknik Negeri Bali.

Perbawa, andika. 2010. Pengembangan desa perancak sebagai desa wisata, kecamatan jembrana, kabupaten jembrana. Skripsi. Unud.

Pereda, Maria. 2007.Service Quality in Higher Education, The Experience of Overseas Students.journal of Hospitality, Leisure, Sport and Tourism Education. Internasional Journal of 